\title{
Long-term oxygen therapy in COPD patients: population-based cohort study on mortality
}

This article was published in the following Dove Press journal:

International Journal of COPD

\author{
Nikolay Pavlov' \\ Alan Gary Haynes ${ }^{2,3}$ \\ Armin Stucki ${ }^{4}$ \\ Peter Jüni ${ }^{5}$ \\ Sebastian Robert Ott ${ }^{1}$ \\ 'Department of Pulmonary Medicine, \\ University Hospital (Inselspital), \\ University of Bern, Bern, Switzerland; \\ ${ }^{2}$ CTU Bern, University of Bern, Bern, \\ Switzerland; Institute of Social \\ and Preventive Medicine (ISPM), \\ University of Bern, Bern, Switzerland; \\ ${ }^{4}$ Department of Internal Medicine, \\ Spital Thun, Thun, Switzerland; \\ ${ }^{5}$ Applied Health Research Centre, \\ Li Ka Shing Knowledge Institute of \\ St Michael's Hospital, Department \\ of Medicine, University of Toronto, \\ Toronto, ON, Canada
}

\begin{abstract}
Purpose: Chronic obstructive pulmonary disease (COPD) is the fourth leading cause of death worldwide and is associated with a growing and substantial socioeconomic burden. Long-term oxygen therapy (LTOT), recommended by current treatment guidelines for COPD patients with severe chronic hypoxemia, has shown to reduce mortality in this population. The aim of our study was to assess the standardized mortality ratios of incident and prevalent LTOT users and to identify predictors of mortality.
\end{abstract}

Patients and methods: We conducted a 2-year follow-up population-based cohort study comprising all COPD patients receiving LTOT in the canton of Bern, Switzerland. Comparing age- and sex-adjusted standardized mortality ratios, we examined associations between all-cause mortality and patient characteristics at baseline. To avoid immortal time bias, data for incident (receiving LTOT $<6$ months) and prevalent users were analyzed separately.

Results: At baseline, 475 patients ( $20 \%$ incident users, $n=93$ ) were receiving LTOT because of COPD (48/100,000 inhabitants). Mortality of incident and prevalent LTOT users was $41 \%$ versus $27 \%$, respectively, $p<0.007$, and standardized mortality ratios were $8.02(95 \% \mathrm{CI}$ : 5.64-11.41) versus 5.90 (95\% CI: 4.79-7.25), respectively. Type 2 respiratory failure was associated with higher standardized mortality ratios among incident LTOT users $(60.57,95 \% \mathrm{CI}$ : $11.82-310.45, p=0.038)$.

Conclusion: Two-year mortality rate of COPD patients on incident LTOT was somewhat lower in our study than in older cohorts but remained high compared to the general population, especially in younger patients receiving LTOT $<6$ months. Type 2 respiratory failure was associated with mortality.

Keywords: COPD, long-term oxygen therapy, mortality, type 2 respiratory failure

\section{Introduction}

Chronic obstructive pulmonary disease (COPD) is the fourth leading cause of death worldwide and is associated with a substantial and growing socioeconomic burden. ${ }^{1}$ It is projected that mortality from COPD will continuously increase and become the world's third leading cause of mortality by $2030 .^{2}$ Disease progression usually leads to severe hypoxemia, presenting with symptoms such as dyspnea, reduced exercise tolerance, daytime fatigue and sleepiness, impaired intellectual faculties, anxiety and depression. Long-term oxygen therapy (LTOT) has been found to reduce overall mortality and to improve cognitive function and emotional status in COPD patients with severe chronic hypoxemia and is recommended for this population by current treatment guidelines. ${ }^{1,3-6}$ Survival of such patients remains poor despite LTOT. The overall age-standardized COPD mortality ratio for men and women in Europe is about 18 per 100,000 per year with a great variability across different countries. ${ }^{7}$ Factors associated with mortality in patients with severe COPD include age, sex, lung function,
Correspondence: Nikolay Pavlov

Department of Pulmonary

Medicine, University Hospital

(Inselspital), University of Bern,

3010 Bern, Switzerland

$\mathrm{Tel}+4$ I 3 I 6328099

Fax +4| 3| 632 |404

Email nikolay.pavlov@insel.ch 
malnutrition, concomitant malignancy, smoking habits, hypoxemia and exercise tolerance. ${ }^{8}$

The presence of severe hypoxemia in many patients with end-stage COPD requiring supplemental oxygen easily explains the association of LTOT with a higher mortality. ${ }^{9-11}$ However, only few studies addressed mortality in this subgroup of patients. Mortality rates of patients receiving LTOT vary between $12 \%$ and $31 \%$ after 1 year, between $22 \%$ and $62 \%$ after 2 years and between $36 \%$ and $81 \%$ after 5 years..$^{8,12-19}$ There is inconsistent data on the sex-related differences in survival on LTOT for COPD as well as on the association of hypercapnia with excess mortality. Lower body mass index, subjective intensity of dyspnea, severity of hypoxemia and comorbidities at baseline proved to be predictors of higher mortality in patients with LTOT. ${ }^{8,15-17,20-24}$

A better understanding of the natural course of COPD at its end stage and identification of potentially modifiable risk factors for excess mortality could improve patient management and give insight for novel care strategies for patients with COPD on LTOT. We aimed at calculating populationbased estimates of overall mortality and standardized mortality ratios of incident and prevalent LTOT users because of COPD and identifying risk factors associated with excess mortality.

\section{Patients and methods Study design and patients}

This is a population-based prospective cohort study including all patients with COPD requiring LTOT in the canton of Bern, Switzerland, between March 2012 and April 2014. At that time, all patients on LTOT in the canton of Bern were supplied and cared for by the Lungenliga Bern (LLB), an independent nonprofit organization engaged in providing medical, medico-technical and nursing services to patients with chronic and acute lung diseases and participating in prevention and promotion of respiratory health. One of the LLB's primary services is the management of LTOT. Prescriptions are made and renewed yearly by respiratory specialists in conformity with national and international guidelines ${ }^{1,25,26}$ and sent to LLB, where patient data are registered. LLB is responsible for providing oxygen delivery device and counseling for the patient.

\section{Data collection}

Baseline data were derived from fully anonymized copies of the last prescription form of all patients on LTOT in the canton of Bern as per March 12, 2012. Every prescription had been annotated with an identity number by LLB and we were blinded to all personal information. Baseline data included age, sex, diagnosis, presence of cor pulmonale, pulmonary function tests, arterial blood gas analysis with and without supplemental oxygen at rest and during exertion, type of oxygen delivery system and prescribed oxygen dose. Rental date of the oxygen delivery device was considered as beginning date of LTOT, as this date always coincides with the delivery of the device and patient's instruction. Information about the oxygen dose effectively used by each patient documented in home visit protocols by the LLB was additionally supplied. Compliance with oxygen therapy was defined as using oxygen dose as prescribed or for $\geq 16$ hours/day. Type 2 respiratory failure was defined as oxygen partial pressure $\left(\mathrm{PaO}_{2}\right)<60 \mathrm{mmHg}$ and carbon dioxide partial pressure $\left(\mathrm{PaCO}_{2}\right)>55 \mathrm{mmHg}$. Death events were reported on a regular basis by the LLB using the provided prescription identity number. Data on vital status were prospectively collected for a 2-year period (March 2012-April 2014). This study was performed in accordance with Swiss laws (Federal Act on Research involving Human Beings 810.30 ) and the principles of good clinical practice. At the time of study design and realization, studies only using fully anonymized health data were not subject to legal restrictions. Thus, written informed consent was not required as only anonymized, already existing data were used.

Eligible were all patients aged $>18$, receiving LTOT because of COPD. Patients who started LTOT within 6 months prior to data collection were accounted for as incident users. Patients receiving LTOT for longer than 6 months were defined as prevalent users.

\section{Statistical analysis}

To compare mortality rates of patients with COPD receiving LTOT and the general population of the Canton of Bern, we calculated standardized mortality ratios (the ratio of observed to expected number of deaths) and the corresponding 95\% confidence interval (CI). Expected numbers of deaths according to age (in 10-year age bands) and sex were derived from the Swiss Federal Statistical Office 2012 mortality data (https:// www.bfs.admin.ch/bfs/en/home/statistics/health/state-health/ mortality-causes-death.html). Using age- and sex-adjusted standardized mortality ratios, we analyzed all-cause mortality according to patient characteristics at baseline (sex, age, type 2 respiratory failure, cor pulmonale, $\mathrm{PaO}_{2}$ at rest while breathing room air $\leq 60 \mathrm{mmHg}, \mathrm{PaCO}_{2}$ at rest while breathing room air $\geq 55 \mathrm{mmHg}, \mathrm{PaO}_{2}$ after 30 min supplemental oxygen $\leq 60 \mathrm{mmHg}, \mathrm{PaCO}_{2}$ after $30 \mathrm{~min}$ supplemental oxygen $\geq 55 \mathrm{mmHg}$ ) using two-sided $Z$-tests. Missing data were accounted for by using multiple imputation according to Rubin's rules, with age, sex, recommended oxygen dose, compliance 
with the prescribed oxygen dose, whether the patient died, presence of cor pulmonale, presence of type 2 respiratory failure, $\mathrm{PaO}_{2}$ and $\mathrm{PaCO}_{2}$ at rest while breathing room air and after 30 min of supplemental oxygen, to create 10 imputed datasets using chained equations. To address immortal time bias in prevalent cases,${ }^{27}$ data for incident and prevalent LTOT users were analyzed separately throughout.

In an age- and sex-adjusted multivariable Cox regression model, we examined the hazard of death in the incident and prevalent LTOT groups. Additionally, we performed a logistic regression for the age-related probability of death of both groups and compared it with the mortality pattern of the general population of the canton of Bern (Swiss Federal Statistical Office, https://www.bfs.admin.ch/bfs/ en/home/statistics/health/state-health/mortality-causesdeath.html) using the age band of the study population. All $p$-values $<0.05$ were considered significant.

\section{Results \\ Patients' characteristics and LTOT prevalence}

On March 12, 2012, a total of 771 patients were treated with LTOT in the Canton of Bern (total population 992,617 inhabitants [www.be.ch/statistik]). Nine patients (1\%) were aged $<18$ years and 287 patients (37\%) had a primary diagnosis other than COPD leading to LTOT (Figure 1). The remaining 475 (62\%) patients complied with the eligibility criteria and were included. Accordingly, the prevalence of LTOT because of COPD was 47.9/100,000 inhabitants. Ninety three patients (20\%) who had recently started LTOT ( $<6$ months prior to the reference date) were considered incident users. Three hundred eighty two patients $(80 \%)$ who had been treated with LTOT for longer than 6 months were considered prevalent users.

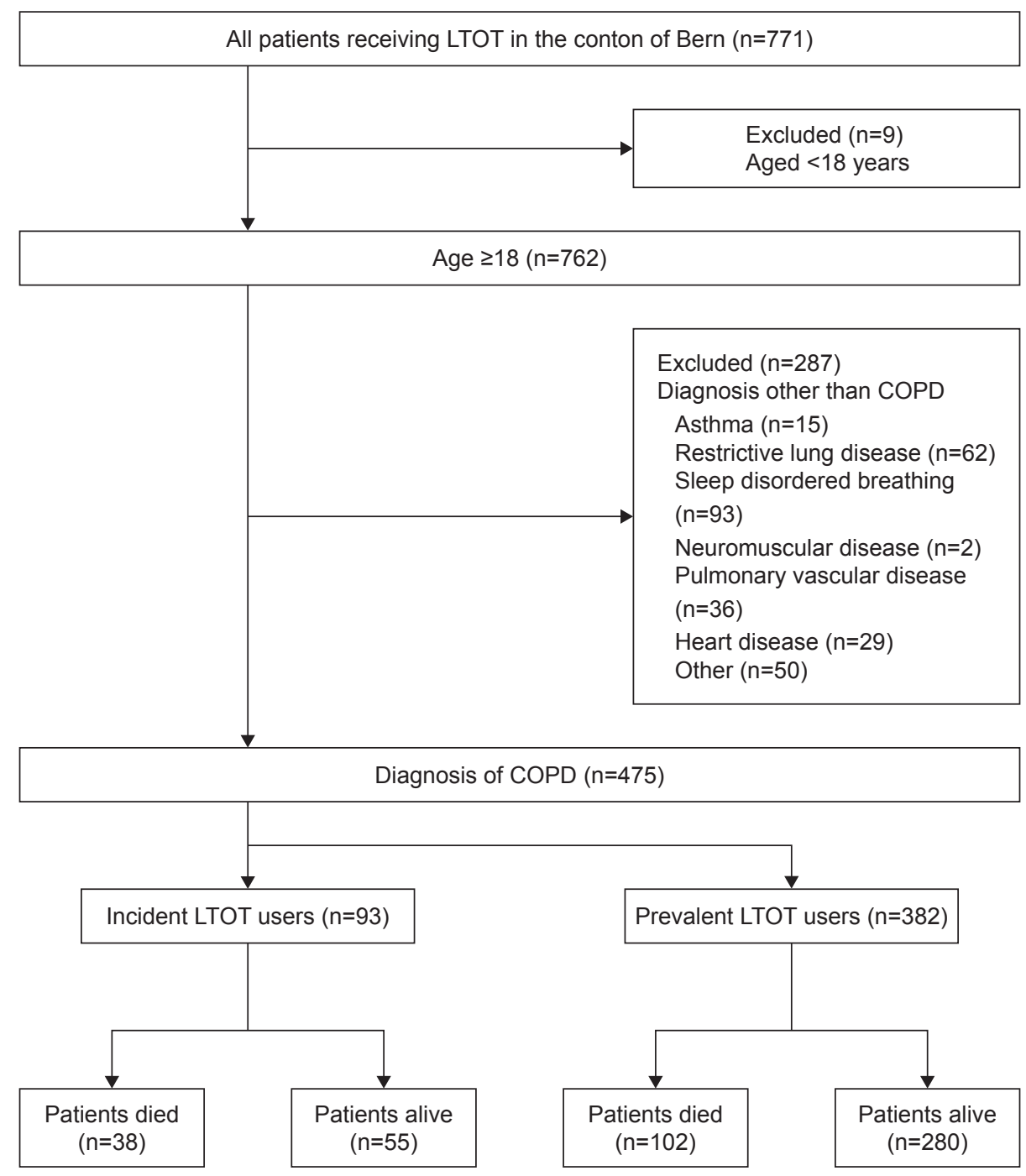

Figure I Flow of participants through different stages of the study.

Abbreviations: COPD, chronic obstructive pulmonary disease; LTOT, long-term oxygen therapy. 
Baseline characteristics according to group assignment and survival status at the end of follow-up are shown in Table 1. Overall, the cohort comprised patients with COPD GOLD Stages 2-4 with a mean age of $69 \pm 10$ years; $68 \%$ were male. Mean forced expiratory volume in 1 second $\left(\mathrm{FEV}_{1}\right)$ was $43.1 \% \pm 17.1 \%$ predicted and 243 patients $(65 \%)$ presented with a concomitant cor pulmonale. The LTOT compliance was $70 \%$ with no significant differences between the two groups. At baseline, 88 patients (21\%) presented with a $\mathrm{PaO}_{2}>60 \mathrm{mmHg}$ while breathing room air, 18 patients $(4 \%)$ were hypercapnic $\left(\mathrm{PaCO}_{2}>55 \mathrm{mmHg}\right)$ while breathing room air and 35 patients (11\%) developed hypercapnia on LTOT. No patient was lost to follow-up and LTOT was continued in all patients during the study period.

\section{Mortality}

At the end of the 2-year follow-up period, 140 patients (29\%) had died. Mortality was significantly higher in incident compared to prevalent LTOT users (41\% versus 27\%; $p=0.007)$. In age- and sex-adjusted analyses, this was confirmed (hazard ratio $=1.66,95 \% \mathrm{CI}: 1.14-2.41, p=0.008$ ). The number of observed and expected deaths and the corresponding age- and sex-standardized mortality ratios for each variable are shown in Figure 2 for both groups. The increase in age- and sex-standardized all-cause mortality appeared more pronounced in incident than in prevalent LTOT users, even though CI overlapped widely (standardized mortality ratio 8.02 [95\% CI: 5.64-11.41] versus 5.90 [95\% CI: 4.79-7.25], respectively).

\section{Risk factors}

In the incident LTOT group, the standardized mortality ratio was significantly higher in patients with type 2 respiratory failure at LTOT initiation (60.57 [95\% CI: 11.82-310.45] versus 7.32 [95\% CI: 4.97-10.79], $p=0.038$ ) and in patients aged $<65$ years as compared with older patients $(23.38$ [95\% CI: 11.94-45.75] versus 6.50 [95\% CI: 4.29-9.84], $p=0.005)$. We found little evidence to suggest that agestandardized mortality ratios differed between men and women. Neither presence of cor pulmonale nor isolated hypoxemia nor hypercapnia had a significant influence on the standardized mortality ratios.

Among prevalent LTOT users, the standardized mortality ratio was again significantly higher in patients aged $<65$ years as compared with older patients (11.35 [95\% CI: 7.29-17.65] versus 5.24 [95\% CI: 4.14-6.65], $p=0.008)$, while sex, the

Table I Patients' characteristics at baseline

\begin{tabular}{|c|c|c|c|c|c|c|}
\hline & \multirow{2}{*}{$\begin{array}{l}\text { All patients } \\
(n=475)\end{array}$} & \multicolumn{2}{|c|}{ Incident LTOT users $(\mathrm{n}=93)$} & \multicolumn{2}{|c|}{ Prevalent LTOT users $(n=382)$} & \multirow[t]{2}{*}{$p$-value } \\
\hline & & Patients alive & Patients died & Patients alive & Patients died & \\
\hline & & $\mathrm{n}=55(59 \%)$ & $n=38(41 \%)$ & $\mathrm{n}=280(73 \%)$ & $\mathrm{n}=102(27 \%)$ & \\
\hline Age (years) & $69.0 \pm 10.0$ & $71.1 \pm 9.9$ & $71.8 \pm 8.4$ & $66.8 \pm 10.2$ & $72.7 \pm 8.5$ & $<0.001$ \\
\hline Elderly ( $>65$ years of age) & $296(62 \%)$ & $36(65 \%)$ & $28(74 \%)$ & $|5|$ (54\%) & $8 \mathrm{I}(79 \%)$ & $<0.001$ \\
\hline Sex (male) & $323(68 \%)$ & $38(69 \%)$ & 30 (79\%) & $184(66 \%)$ & 71 (70\%) & 0.405 \\
\hline \multicolumn{7}{|l|}{ Oxygen delivery device } \\
\hline Liquid oxygen & $211(44 \%)$ & 14 (25\%) & $4(11 \%)$ & 147 (53\%) & $46(45 \%)$ & $<0.001$ \\
\hline \multirow[t]{2}{*}{ Concentrator } & $264(56 \%)$ & $4 \mathrm{I}(75 \%)$ & $34(89 \%)$ & 133 (48\%) & $56(55 \%)$ & $<0.001$ \\
\hline & $\begin{array}{l}\text { Data available, } \\
\text { value* }\end{array}$ & $\begin{array}{l}\text { Data available, } \\
\text { value* }\end{array}$ & $\begin{array}{l}\text { Data available, } \\
\text { value* }\end{array}$ & $\begin{array}{l}\text { Data available, } \\
\text { value* }\end{array}$ & $\begin{array}{l}\text { Data available, } \\
\text { value* }\end{array}$ & \\
\hline Cor pulmonale & $373,243(65 \%)$ & $48,29(60 \%)$ & $31,16(52 \%)$ & $214,143(67 \%)$ & $80,55(69 \%)$ & 0.296 \\
\hline Vital capacity (\%) & $411,64.0 \pm 22.9$ & $49,58.9 \pm 24.3$ & $33,63.8 \pm 22.0$ & $243,64.8 \pm 22.2$ & $86,64.8 \pm 24.1$ & 0.417 \\
\hline $\mathrm{FEV}_{1}(\%)$ & $417,43.1 \pm 17.1$ & $51,45.9 \pm 18.1$ & $34,40.0 \pm 15.2$ & $246,42.4 \pm 16.5$ & $86,44.7 \pm 18.9$ & 0.306 \\
\hline $\begin{array}{l}\mathrm{PaO}_{2} \text { at rest while breathing } \\
\text { room air } \leq 60 \mathrm{mmHg}\end{array}$ & $424,336(79 \%)$ & $5 \mathrm{I}, 43(84 \%)$ & $33,24(73 \%)$ & $252,201(80 \%)$ & $88,68(77 \%)$ & 0.594 \\
\hline $\begin{array}{l}\mathrm{PaCO}_{2} \text { at rest while breathing } \\
\text { room air } \geq 55 \mathrm{mmHg}\end{array}$ & $423,18(4 \%)$ & $50, I(2 \%)$ & $34,4(12 \%)$ & $25 \mathrm{I}, 9(4 \%)$ & $88,4(5 \%)$ & 0.131 \\
\hline $\begin{array}{l}\mathrm{PaO}_{2} \text { after } 30 \mathrm{~min} \text { supplemental } \\
\text { oxygen } \leq 60 \mathrm{mmHg}\end{array}$ & $315,54(17 \%)$ & $36,9(25 \%)$ & 22,3 (I4\%) & $186,28(15 \%)$ & $7 \mathrm{I}, 14(20 \%)$ & 0.447 \\
\hline $\begin{array}{l}\mathrm{PaCO}_{2} \text { after } 30 \mathrm{~min} \text { supplemental } \\
\text { oxygen } \geq 55 \mathrm{mmHg}\end{array}$ & $317,35(11 \%)$ & $36,3(8 \%)$ & $23,5(22 \%)$ & $|87,2|(\mid 1 \%)$ & $71,6(8 \%)$ & 0.329 \\
\hline Oxygen dose at rest (L) & $457,2.0 \pm 1.0$ & $53,2.1 \pm 1.2$ & $37,2.0 \pm 0.9$ & $268,1.9 \pm 0.8$ & $99,2.3 \pm 1.4$ & 0.003 \\
\hline Type 2 respiratory failure & $424,15(4 \%)$ & $5 \mathrm{I}, \mathrm{I}(2 \%)$ & $33,2(6 \%)$ & $252,8(3 \%)$ & $88,4(5 \%)$ & 0.718 \\
\hline Compliance to LTOT & $475,333(70 \%)$ & $55,36(65 \%)$ & $38,26(68 \%)$ & $280,191(68 \%)$ & $102,80(78 \%)$ & 0.215 \\
\hline
\end{tabular}

Notes: Type 2 respiratory failure was defined as $\mathrm{PaO}_{2}<60 \mathrm{mmHg}$ and $\mathrm{PaCO}_{2}>55 \mathrm{mmHg}$. *Values are mean with a standard deviation for continuous variables and percentage for categorical variables.

Abbreviations: $\mathrm{FEV}_{1}$, forced expiratory volume in I second; LTOT, long-term oxygen therapy; $\mathrm{PaCO}_{2}$, carbon dioxide partial pressure; $\mathrm{PaO}$, oxygen partial pressure. 


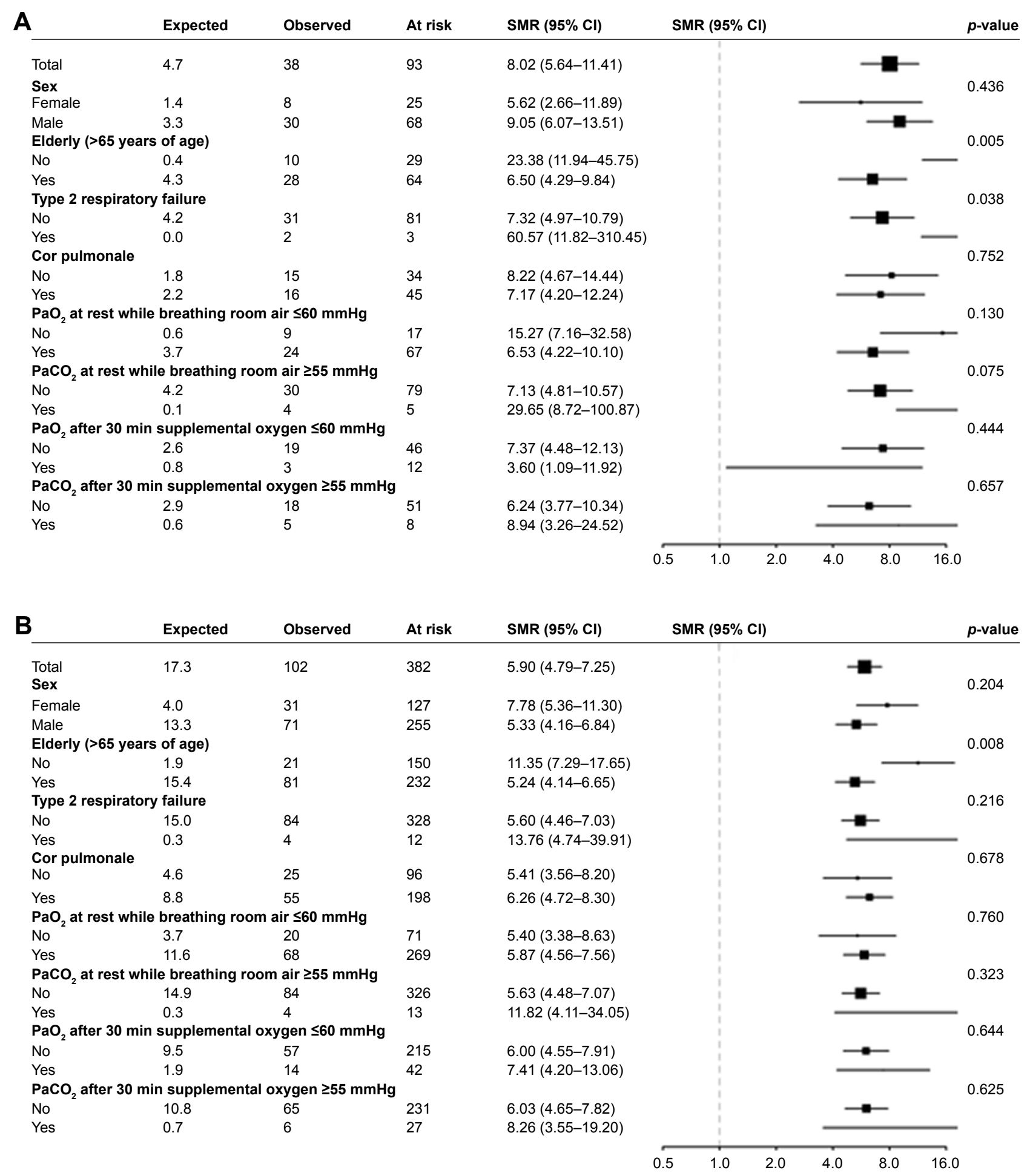

Figure 2 Age- and sex-standardized mortality ratios for incident LTOT users (A) and prevalent LTOT users (B).

Abbreviations: $\mathrm{Cl}$, confidence interval; LTOT, long-term oxygen therapy; $\mathrm{PaCO}_{2}$, carbon dioxide partial pressure; $\mathrm{PaO}_{2}$, oxygen partial pressure; SMR, standardized mortality ratio.

presence of type 2 respiratory failure, cor pulmonale, isolated hypoxemia and hypercapnia did not result in significant differences in standardized mortality ratios. In neither cohort, there was an association between initial $\mathrm{FEV}_{1}$ and compliance to LTOT with mortality (data not shown).

\section{Mortality patterns}

The age-specific probability of death of incident and prevalent LTOT users compared with the general population is shown in Figure 3. The mortality pattern of incident LTOT users showed a linear association with slow progression and 

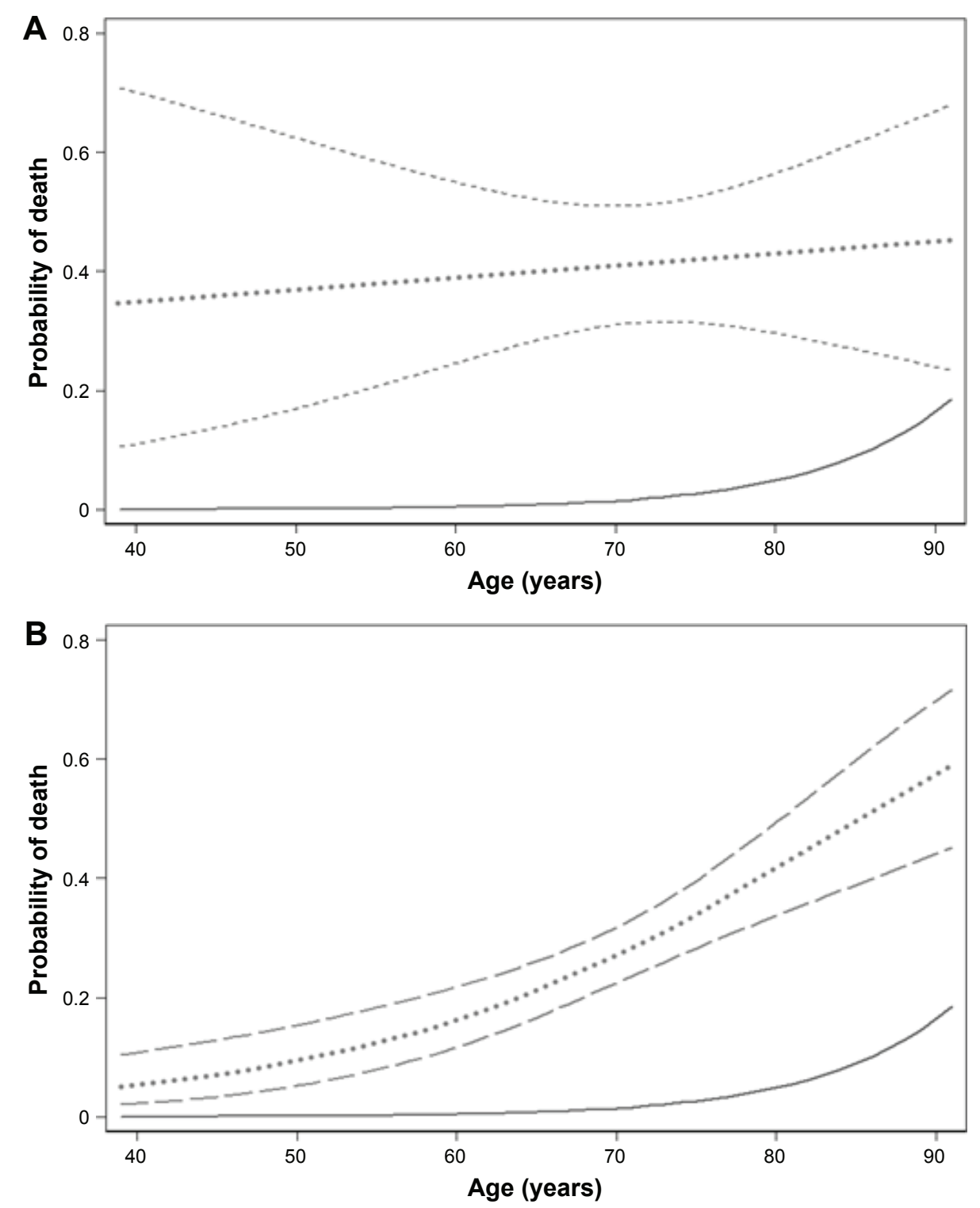

General population $\ldots$ Incident/prevalent LTOT users $\quad \ldots=m=$ Confidence interval

Figure 3 Age-related probability of death among incident LTOT users (A) and prevalent LTOT users (B).

Abbreviation: LTOT, long-term oxygen therapy.

a broad distribution of the CIs with disproportionately high mortality in younger age bands. In the prevalent LTOT group, the probability of death was at its lowest with younger age (40-50) and rose steadily thereafter. The age-related probability of death of the prevalent LTOT users corresponded to the mortality pattern of the general population yet remaining higher at any age.

\section{Discussion}

\section{Main results}

In the current study, we found a disproportionately high mortality shortly after initiation of LTOT compared with the general population in one of the largest cohorts of COPD patients on LTOT during a 2-year follow-up. We found different age-related mortality patterns for incident and prevalent LTOT users compared with the general population. Type 2 respiratory failure was identified as an independent risk factor for excess mortality in both the incident and the prevalent LTOT group.

\section{Strengths and limitations}

Strengths of the present study include the population-based design and the large size of the cohort. No patient was lost to follow-up and no LTOT was discontinued. The inclusion 
of patients receiving LTOT outside current international guidelines represents everyday practice and the results of our study are based on real-life data. ${ }^{28,29}$ The analysis was adjusted for age and sex and missing data accounted for using multiple imputation. One limitation of the study consists in the inclusion of patients with different LTOT durations. A combination of incident and prevalent LTOT users would result in immortal time bias: ${ }^{27}$ patients in the prevalent LTOT group lived long enough to be included in the cohort, giving them a survival advantage over the incident LTOT users. Therefore, we analyzed incident and prevalent LTOT users separately. Another limitation is the lack of data on comorbidities and cause of death in our population. This is owed to the fact that only fully anonymized data derived from LTOT prescription forms were used and information on these issues was not part of the LTOT prescription procedure. In addition, information on simultaneously administered medication was not available. However, as guidelines for LTOT prescription in Switzerland require optimized treatment of the underlying disease prior to LTOT initiation and reimbursement by compulsory health insurances, we believe that the impact of comedication on the outcome can be neglected. Finally, information on the use of noninvasive ventilation in hypercapnic patients was missing, and therefore, its association with mortality could not be examined.

\section{Context}

The prevalence of LTOT because of COPD in our study was identical to a recent report. ${ }^{30}$ The overall mortality rate of incident LTOT users at 2 years in our study was somewhat lower compared to most older cohorts of similar size (41\% versus $46 \%-62 \%),{ }^{16-19}$ in accordance with the observed declining mortality rates of COPD populations in the last two decades. ${ }^{31,32}$ Two earlier studies showed lower mortality rates $(22 \%$ and $27 \%$ ) but investigated a much smaller population and did not distinguish between incident and prevalent LTOT users. ${ }^{14,24}$ The trend toward mortality reduction over time could be due to declining smoking rates and improving management of patients with an end-stage pulmonary disease and relevant comorbidities over the years. Geographical differences (the referred studies were conducted in Australia, Belgium, Denmark, Italy, Norway and Sweden), including patient characteristics and health care providing, could further explain the wide range of mortality rates.

As expected, the standardized mortality ratios of oxygendependent COPD patients (both incident and prevalent LTOT users) in the present study were notably higher than the reported standardized mortality ratios of an overall COPD
Table 2 Differences of the standardized mortality ratios of oxygen-dependent COPD patients from our cohort compared with an overall COPD population

\begin{tabular}{|c|c|c|c|}
\hline & \multicolumn{3}{|c|}{ Standardized mortality ratios } \\
\hline & $\begin{array}{l}\text { Incident } \\
\text { LTOT users }\end{array}$ & $\begin{array}{l}\text { Prevalent } \\
\text { LTOT users }\end{array}$ & $\begin{array}{l}\text { Overall COPD } \\
\text { population }^{33}\end{array}$ \\
\hline Female & 5.62 & 7.78 & 2.7 \\
\hline Male & 9.05 & 5.33 & 4.8 \\
\hline
\end{tabular}

Abbreviations: COPD, chronic obstructive pulmonary disease; LTOT, long-term oxygen therapy.

cohort comprising GOLD stages 2-4 (Table 2). The lack of statistically significant differences of standardized mortality ratios between males and females in our cohort was inconsistent with current literature but the nominally higher standardized mortality ratios in female prevalent LTOT users seem to support recent findings. ${ }^{33}$ It has been shown that sex-related differences in survival become more apparent after 3 years of follow-up, meaning that the duration of our study might not have been long enough to detect them. ${ }^{23}$ Other studies, however, show a clear survival advantage for women. ${ }^{14,16,20,30}$ Heterogeneous population characteristics, the abovementioned geographic differences and inconsistent covariates in the analysis could offer a possible explanation.

\section{Risk factors}

As discussed above, immortal time bias resulted in prevalent LTOT users having lower standardized mortality ratios than incident LTOT users. Therefore, the relatively benign prognosis of prevalent users lacks credibility. Conversely, the disproportionately high standardized mortality ratio of incident LTOT users truly reflects the poor prognosis of endstage COPD with development of severe hypoxemia requiring LTOT. A large number of incident LTOT users seem to be at high risk shortly after LTOT initiation. The survivors of this initial period will likely have a prognosis similar to the prognosis of the prevalent LTOT users in our study. Earlier studies showed an association between older age and mortality, ${ }^{16-18,24}$ whereas our study, in accordance to newer data, does not. ${ }^{8,11,23}$ We found higher standardized mortality ratios for patients aged $\leq 65$ in both incident and prevalent LTOT groups. Undoubtedly, this also should be regarded as immortal time bias in elderly prevalent users. Among incident LTOT users, however, the disproportionately high mortality of younger patients aged 40-50 truly reflects the higher risk of this group, with a more pronounced risk factor profile and/or a worse genetic predisposition that eventually resulted in an earlier initiation of LTOT during the life course. As younger adults are accustomed to higher $\mathrm{PaO}_{2}, 34,35$ 
mortality could be explained by the greater difference of $\mathrm{PaO}_{2}$ in severe hypoxemia and a poorer adaptation to the impaired gas exchange.

$\mathrm{FEV}_{1}$ is an independent prognostic factor associated with mortality in the overall COPD population. ${ }^{36}$ Earlier studies found an association between $\mathrm{FEV}_{1}$ and mortality in COPD patients on LTOT. ${ }^{16,24}$ However, results from more recent cohorts as well as our study do not support this finding. ${ }^{8,23}$ We suppose that obstruction severity loses its prognostic value in oxygen-dependent COPD patients and that mortality in this population is influenced by other factors, such as impaired gas exchange, recurrent exacerbations and/or comorbidities. Cor pulmonale in COPD is considered a predictor of poor survival and diminished exercise capacity. $\mathrm{PaO}_{2}$ cutoffs for prescribing LTOT are higher in this subgroup of patients. ${ }^{1,25,26}$ Interestingly, no differences in the mortality of patients with and without cor pulmonale were observed in our study, suggesting that correcting hypoxemia diminishes the additional risk in this subgroup. Improvement in pulmonary hemodynamics and a reduction in pulmonary vascular resistance by LTOT have been shown as a possible underlying pathophysiologic mechanism. ${ }^{37}$ Consistent with previous findings, ${ }^{16}$ persistent hypoxemia under LTOT did not have an influence on mortality in our cohort. Finally, we found nominally higher standardized mortality ratios in incident LTOT users with $\mathrm{PaO}_{2}>60 \mathrm{mmHg}$ at rest while breathing room air.

\section{Clinical and scientific implications}

The disproportionately high mortality of incident LTOT users calls for a closer follow-up and more proactive management of COPD patients in the first months after prescribing LTOT. Deterioration of blood gases is commonly observed during acute exacerbations of COPD with $\mathrm{PaO}_{2}$ remaining low even after clinical stabilization of the patient, leading to the prescription of LTOT. ${ }^{38}$ A recent study demonstrated a higher all-cause 12 -month mortality rate in an overall population of patients with acute exacerbations of COPD, which supports our findings. ${ }^{39} \mathrm{We}$ identified type 2 respiratory failure at baseline as a risk factor associated with excess mortality. Chronic type 2 respiratory failure in COPD is a combination of hypercapnia because of impairment of the ventilatory pump (hyperinflation of the lungs, respiratory muscle weakness, pulmonary cachexia) and hypoxemia caused by alveolar hypoventilation. An acute event, such as an exacerbation associated with an increase of airway obstruction and respiratory workload, could disturb the delicate steady state of the underlying chronic respiratory failure with further impairment of gas exchange that eventually leads to death. Type 2 respiratory failure itself results in increased work of ventilation with reduced oxygen supply to the respiratory muscles creating a vicious cycle.

Chronic hypercapnia alone was not identified as a risk factor in the current study but it causes symptoms such as anxiety, dyspnea, fatigue, daytime sleepiness, depression and confusion. Therefore, it should be prevented by close monitoring and adapting oxygen dose after initiation of LTOT. Noninvasive ventilation use in the subgroup of COPD patients with chronic hypercapnia or type 2 respiratory failure should also be considered, as suggested before. ${ }^{40-43}$ Even though not statistically significant, our results of higher standardized mortality ratios in incident LTOT users with $\mathrm{PaO}_{2}>60 \mathrm{mmHg}$ at rest while breathing room air are alerting. They suggest that usage of LTOT in patients presenting only with exercise-induced hypoxemia, nocturnal hypoxemia or in cases not conforming to international guidelines on the prescription of LTOT could be problematic. Further studies are needed to confirm these results that could be explained by oxygen toxicity and/or by a suppression of the central ventilatory drive.

\section{Conclusion}

Two-year mortality rate of COPD patients on incident LTOT was somewhat lower in our study than in older cohorts but remained high compared to the general population, especially in younger patients receiving LTOT $<6$ months. Therefore, patients recently started on LTOT should receive a closer follow-up in the first months including reevaluation of compliance and indication for oxygen therapy as well as adjustment of the oxygen dose according to blood gas analysis. LTOT should aim for correction of hypoxemia without causing hypercapnia. Closer attention should be paid to type 2 respiratory failure that was associated with mortality. Noninvasive ventilation should be considered early in the management plan of selected patients.

\section{Acknowledgments}

The authors would like to thank Lungenliga Bern for providing the anonymized data for this study. This research did not receive any specific grant from funding agencies in the public, commercial or not-for-profit sectors. The abstract of this paper was presented at the Joint Annual Meeting of the Swiss Society of Cardiology, the Swiss Society of Cardiac and Thoracic Vascular Surgery and the Swiss Society of Pneumology, Lausanne, June 15-17, 2016 as a poster presentation/ conference talk with interim findings. The poster's abstract 
was published in Cardiovascular Medicine, issue 5, supplement 26, 25 May 2016 as well as in Respiration 2016;91:414 468, https://doi.org/10.1159/000446260.

\section{Disclosure}

The authors report no conflicts of interest in this work.

\section{References}

1. From the Global Strategy for the Diagnosis, Management and Prevention of COPD, Global Initiative for Chronic Obstructive Lung Disease (GOLD); 2017. Available from: http://goldcopd.org/

2. World Health Organization. World Health Statistics 2008. Geneva: WHO; 2008.

3. Celli BR, MacNee W. Standards for the diagnosis and treatment of patients with COPD: a summary of the ATS/ERS position paper. Eur Respir J. 2004;23(6):932-946.

4. Continuous or nocturnal oxygen therapy in hypoxemic chronic obstructive lung disease: a clinical trial. Nocturnal Oxygen Therapy Trial Group. Ann Intern Med. 1980;93(3):391-398.

5. Long term domiciliary oxygen therapy in chronic hypoxic cor pulmonale complicating chronic bronchitis and emphysema. Report of the Medica Research Council Working Party. Lancet. 1981;1(8222):681-686.

6. Borak J, Sliwiński P, Tobiasz M, Górecka D, Zieliński J. Psychological status of COPD patients before and after one year of long-term oxygen therapy. Monaldi Arch Chest Dis. 1996;51(1):7-11.

7. Gibson GJ, Loddenkemper R, Lundbäck B, Sibille Y. Respiratory health and disease in Europe: the new European Lung White Book. Eur Respir J. 2013;42(3):559-563.

8. Coleta KD, Silveira LV, Lima DF, Rampinelli EA, Godoy I, Godoy I. Predictors of first-year survival in patients with advanced COPD treated using long-term oxygen therapy. Respir Med. 2008;102(4):512-528.

9. Tsimogianni AM, Papiris SA, Stathopoulos GT, Manali ED, Roussos C, Kotanidou A. Predictors of outcome after exacerbation of chronic obstructive pulmonary disease. J Gen Intern Med. 2009;24(9):1043-1048.

10. Yohannes AM, Baldwin RC, Connolly M. Mortality predictors in disabling chronic obstructive pulmonary disease in old age. Age Ageing. 2002;31(2):137-140.

11. Gulbas G, Gunen H, In E, Kilic T. Long-term follow-up of chronic obstructive pulmonary disease patients on long-term oxygen treatment Int J Clin Pract. 2012;66(2):152-157.

12. Janssens JP, Rochat T, Frey JG, Dousse N, Pichard C, Tschopp JM Health-related quality of life in patients under long-term oxygen therapy: a home-based descriptive study. Respir Med. 1997;91(10):592-602.

13. Keller R, Ragaz A, Borer P. Predictors for early mortality in patients with long-term oxygen home therapy. Respiration. 1985;48(3):216-221.

14. Hjalmarsen A, Melbye H, Wilsgaard T, Holmboe JH, Opdahl R, Viitanen M Prognosis for chronic obstructive pulmonary disease patients who receive long-term oxygen therapy. Int J Tuberc Lung Dis. 1999;3(12): $1120-1126$.

15. Aida A, Miyamoto K, Nishimura M, Aiba M, Kira S, Kawakami Y. Prognostic value of hypercapnia in patients with chronic respiratory failure during long-term oxygen therapy. Am J Respir Crit Care Med. 1998; 158(1):188-193.

16. Crockett AJ, Cranston JM, Moss JR, Alpers JH. Survival on long-term oxygen therapy in chronic airflow limitation: from evidence to outcomes in the routine clinical setting. Intern Med J. 2001;31(8):448-454.

17. Ström K, Boe J. Quality assessment and predictors of survival in long-term domiciliary oxygen therapy. The Swedish Society of Chest Medicine. Eur Respir J. 1991;4(1):50-58.

18. Dubois P, Jamart J, Machiels J, Smeets F, Lulling J. Prognosis of severely hypoxemic patients receiving long-term oxygen therapy. Chest. 1994;105(2):469-474.

19. Ringbaek TJ, Lange P. The impact of the Danish Oxygen Register on adherence to guidelines for long-term oxygen therapy in COPD patients. Respir Med. 2006;100(2):218-225.
20. Ekström MP, Jogréus C, Ström KE. Comorbidity and sex-related differences in mortality in oxygen-dependent chronic obstructive pulmonary disease. PLoS One. 2012;7(4):e35806.

21. Ahmadi Z, Bornefalk-Hermansson A, Franklin KA, Midgren B, Ekström MP. Hypo- and hypercapnia predict mortality in oxygendependent chronic obstructive pulmonary disease: a population-based prospective study. Respir Res. 2014;15:30.

22. Skwarski K, MacNee W, Wraith PK, Sliwinski P, Zielinski J. Predictors of survival in patients with chronic obstructive pulmonary disease treated with long-term oxygen therapy. Chest. 1991;100(6):1522-1527.

23. Machado MC, Krishnan JA, Buist SA, et al. Sex differences in survival of oxygen-dependent patients with chronic obstructive pulmonary disease. Am J Respir Crit Care Med. 2006;174(5):524-529.

24. Dallari R, Barozzi G, Pinelli G, et al. Predictors of survival in subjects with chronic obstructive pulmonary disease treated with long-term oxygen therapy. Respiration. 1994;61(1):8-13.

25. Russi EW, Karrer W, Brutsche M, et al. Swiss respiratory society. diagnosis and management of chronic obstructive pulmonary disease: the Swiss guidelines. Official guidelines of the swiss respiratory society. Respiration. 2013;85:160-174.

26. Hardinge M, Suntharalingam J, Wilkinson T; British Thoracic Society. Guideline update: the British Thoracic Society Guidelines on home oxygen use in adults. Thorax. 2015;70(6):589-591.

27. Hanley JA, Foster BJ. Avoiding blunders involving 'immortal time'. Int J Epidemiol. 2014;43(3):949-961.

28. Oba Y, Salzman GA, Willsie SK. Reevaluation of continuous oxygen therapy after initial prescription in patients with chronic obstructive pulmonary disease. Respir Care. 2000;45(4):401-406.

29. Verduri A, Ballerin L, Simoni M, et al. Poor adherence to guidelines for long-term oxygen therapy (LTOT) in two Italian university hospitals. Intern Emerg Med. 2014;9(3):319-324.

30. Ringbaek TJ, Lange P. Trends in long-term oxygen therapy for COPD in Denmark from 2001 to 2010. Respir Med. 2014;108(3):511-516.

31. Doucet M, Rochette L, Hamel D. Incidence, prevalence, and mortality trends in chronic obstructive pulmonary disease over 2001 to 2011: a public health point of view of the burden. Can Respir J. 2016;2016:7518287.

32. López-Campos JL, Ruiz-Ramos M, Soriano JB. Mortality trends in chronic obstructive pulmonary disease in Europe, 1994-2010: a joinpoint regression analysis. Lancet Respir Med. 2014;2(1):54-62.

33. Ringbaek T, Seersholm N, Viskum K. Standardised mortality rates in females and males with COPD and asthma. Eur Respir J. 2005;25(5): 891-895.

34. Loew PG, Thews G. The dependency of the arterial oxygen pressure on age in the working population. Klin Wochenschr. 1962;40: 1093-1098.

35. Sorbini CA, Grassi V, Solinas E, Muiesan G. Arterial oxygen tension in relation to age in healthy subjects. Respiration. 1968;25(1):3-13.

36. Dolan S, Varkey B. Prognostic factors in chronic obstructive pulmonary disease. Curr Opin Pulm Med. 2005;11(2):149-152.

37. Zieliński J, Tobiasz M, Hawryłkiewicz I, Sliwiński P, Pałasiewicz G. Effects of long-term oxygen therapy on pulmonary hemodynamics in COPD patients: a 6-year prospective study. Chest. 1998;113(1): 65-70.

38. Levi-Valensi P, Weitzenblum E, Pedinielli JL, Racineux JL, Duwoos H. Three-month follow-up of arterial blood gas determinations in candidates for long-term oxygen therapy. A multicentric study. Am Rev Respir Dis. 1986;133(4):547-551.

39. Schmidt SA, Johansen MB, Olsen M, et al. The impact of exacerbation frequency on mortality following acute exacerbations of COPD a registry-based cohort study. BMJ Open. 2014;4(12):e006720.

40. McEvoy RD, Pierce RJ, Hillman D, et al. Australian trial of non-invasive Ventilation in Chronic Airflow Limitation (AVCAL) Study Group. Nocturnal non-invasive nasal ventilation in stable hypercapnic COPD: a randomised controlled trial. Thorax. 2009;64(7):561-566.

41. Funk GC, Breyer MK, Burghuber OC, et al. Long-term non-invasive ventilation in COPD after acute-on-chronic respiratory failure. Respir Med. 2011;105(3):427-434. 
42. Köhnlein T, Windisch W, Köhler D, et al. Non-invasive positive pressure ventilation for the treatment of severe stable chronic obstructive pulmonary disease: a prospective, multicentre, randomised, controlled clinical trial. Lancet Respir Med. 2014;2(9):698-705.
43. Murphy PB, Rehal S, Arbane G, et al. Effect of home noninvasive ventilation with oxygen therapy vs. oxygen therapy alone on hospital readmission or death after an acute COPD exacerbation a randomized clinical trial. JAMA. 2017;317(21):2177-2186.

\section{Publish your work in this journal}

The International Journal of COPD is an international, peer-reviewed journal of therapeutics and pharmacology focusing on concise rapid reporting of clinical studies and reviews in COPD. Special focus is given to the pathophysiological processes underlying the disease, intervention programs, patient focused education, and self management protocols.
This journal is indexed on PubMed Central, MedLine and CAS. The manuscript management system is completely online and includes a very quick and fair peer-review system, which is all easy to use. Visit http://www.dovepress.com/testimonials.php to read real quotes from published authors.

Submit your manuscript here: http://www.dovepress.com/international-journal-of-chronic-obstructive-pulmonary-disease-journal 